IJSSP

$39,11 / 12$

1010

Received 4 February 2019

Revised 4 June 2019

Accepted 8 July 2019

\section{Taboo news about Sweden: the transnational assemblage of a racialized spatial imaginary}

\author{
Gavan Titley \\ Department of Media Studies, \\ National University of Ireland Maynooth, Maynooth, Ireland
}

\begin{abstract}
Purpose - The purpose of this paper is to examine the construction of Sweden as a racialised spatial imaginary in the emerging transnational networks of far-right media production. Departing from President Donald Trump's widely reported remarks, in 2017, as to "what happened last night in Sweden", it examines the racializing discourses through which Sweden is constructed as a dark future to be averted; a failed social experiment in immigration and multiculturalism symbolised by the "no-go zones" held to be dotted, yet denied, in its major cities. While the symbolic production of "problem areas" is a familiar dimension of the politics of immigration, the paper explores why Sweden-as-nation is so insistently and intimately associated with its putative no-go zones in what are termed the "revenge fantasies" of the far-right. Further, it argues that these modes of representation cannot be understood without examining the value of Sweden as a news commodity in the expansive far-right media environment.

Design/methodology/approach - The analysis offers the idea of "taboo news" to conceptualise putatively "alternative" news about Sweden which is confirmed through its denial in the mainstream.

Findings - It argues that examining the increasing importance of "taboo news" as a commodity form must be integrated into a reading of how these racializing narratives are produced and circulated.

Originality/value - In so doing, it examines the shaping of this racialised imaginary as a digital assemblage taking shape as a commodity in a newly emerging and under-researched field of communicative and ideological action.
\end{abstract}

Keywords Sweden, Feminism, Racism, Racialization, Digital media, Immigration, Far-right

Paper type Conceptual paper

\section{Introduction}

In August 2018, the BBC's flagship current affairs programme Newsnight produced a special report on Sweden and the "refugee crisis", which opens with the Journalist Gabriel Gatehouse driving across the Öresund bridge from Copenhagen to Malmö. In voiceover, he briefly pays tribute to Sweden's international reputation for progressiveness before voicing an apparently pressing contention, as to whether this "openness and liberalism has created a nightmare that now threatens the very existence of these values themselves". Malmö is the destination, but the report immediately zones in on the central district of Rosengård, which, the voice-over continues, is designated by the police as a "vulnerable area", a designation dismissed as euphemistic by "those who say that what this is [...] is a No-Go zone". The report briskly accumulates initial testimonies from the nightmare before freeze-framing, signalling a sudden narrative break by rewinding the frames with stylised clunkiness, like a glitch in a VCR video tape. Journalists looking for a story, Gatehouse explains, will strive to be fair and accurate, however "we also often go in search of a narrative. And in complex situations, one narrative can eclipse another. Let's go back to Rosengård, and start again”.

Narrative experiments are rare in current affairs reporting, where encoding credibility and maintaining audience attention generally requires fidelity to established generic conventions (Mihelj et al., 2009). The BBC report's reflexive turn is congruent with a pronounced post-2015 intensification, among news agencies and journalists, of meta-commentary on reporting the "refugee crisis", and the potential consequentiality of reporting in the context of remorseless radical right politicisation of asylum-seeking
International Journal of Sociology and Social Policy Vol. 39 No. 11/12, 2019 pp. $1010-1023$ (C) Emerald Publishing Limited 0144-333X

DOI 10.1108/IJSSP-02-2019-0029 
(Kyriakides, 2017; Ojala and Pöyhtäri, 2018). There is also a more overt rationale. The report is entitled "Sweden: truth, lies and manipulated narratives", and after the rewind, the first five minutes are revisited to reveal the judicious edits which appeared to show how, in the initial testimonies, a police officer confirmed the ethnicised nature of crime, and a lawyer agreed that an increase in recorded instances of rape correlating with increases in asylum-seeking. Official statistics - the subject of an earlier BBC news report - and the fully revealed comments of the interviewees clearly contradict these claims, yet the "nightmarish" vision of Sweden beset by ethnic gang violence and sexualised assault is regarded as familiar enough to the BBC's audience to merit this opening narrative gambit. In other words, the production is confident in its unconventional narrative structure because the "nightmare" genre of "stories about Sweden" has achieved newsworthiness on its own terms.

In those opening scenes, this insistent narrative is rehearsed through a montage of comments from what the voiceover describes as a "growing chorus of Sweden sceptics", primarily comprised of right-wing "populist" politicians honing in on Sweden as exemplifying the self-inflicted costs of the post-2015 refugee crisis. As Daniel Trilling (2018) argues, the "refugee crisis" precipitated by the increased scale of movement, particularly as a consequence of the Syrian civil war, along two principal routes - from North Africa to Italy across the Mediterranean, and through Turkey to south-east Europe - is better understood as a "border crisis", that is, a crisis in the system designed to deter, warehouse and filter people before, at and after the border-as-frontier. For the featured politicians, however, Sweden stands as evidence of the consequences of generous "open border" responses that inevitably hurt the excessively liberal host. They include Nigel Farage, who claimed that, because Sweden took in more "young male migrants" that any other country during this period, "Malmö is now the rape capital of Europe" - an excerpt from a live radio broadcast that led to an Ofcom investigation (Batchelor, 2017). However the leader of the chorus, and trigger for the news report, is Donald Trump, who, in February 2017 at a rally in Florida, was widely credited with citing a non-existent terror attack:

We've got to keep our country safe. You look at what's happening in Germany. You look at what's happening last night in Sweden. Sweden, who would believe this? Sweden. They took in large numbers. They're having problems like they never thought possible. You look at what's happening in Brussels. You look at what's happening all over the world. Take a look at Nice. Take a look at Paris.

Trump's citation and the BBC's contestation demonstrate Sweden's prominence in this narrative, and its surfacing in "mainstream" political and journalistic discourse indicates how images of racialised urban spaces in the troubled nation have a political and affective valence in the contemporary construction of transnational, "anti-immigration" politics. This specific prominence is the subject of this paper, which aims to examine the ideological valences and racial fantasies projected onto Sweden, and the mediated assemblage of this racialised spatial imaginary in the transnational far-right media environment. This exploration is guided by two research questions. The first situates the construction of Sweden in a broader spectrum of racialised spaces, and asks:

$R Q 1$. Why are dominant forms of racist projection in the transnational far-right milieu particularly fixated on Sweden-as-nation in the current conjucture?

It demonstrates how nightmare visions of Sweden can be sutured to a spectrum of ideological preoccupations and fantasy structures. This diversity is not, at one level, surprising, as the holding term "the far-right" does little to capture the differences and synergies between movements in transatlantic and transnational perspective. The "newly-reconfigured right" in Europe, according to Liz Fekete (2016), "takes in a range of authoritarian traditions, from social conservatism to fascism, from radical right-wing
Taboo news about Sweden 
IJSSP

$39,11 / 12$

1012

populism to those who continue in the tradition of Franco". Concomitantly, the racial politics of Trump presidency has provided an opportunity for a diversity of movements to mobilise in physical and digital public space, from white nationalist and neo-Nazi movements, to "neo-confederate" and Ku Klux Klan groups, to the highly mediated "alt-right" network that has been able to "mainstream white nationalism and fascism and make them part of popular culture, the media landscape and the national dialogue" (Winter, 2017).

For all this ideological divergence, however, what is striking is that the scalar fixation with Swedish urban areas and cities, and Sweden the nation, is noticeably reproduced across this movement and actor diversity. Sweden functions as a digital palimpsest, inscribed, again and again, with variegated narrative emphases and themes. To probe this further, the second question engages the process of media production, and asks:

$R Q 2$. How is "Sweden" reproduced as a commodity form within a diverse and transnational, far-right cross-media milieu?

The paper offers a specific concept to emphasise the generative interconnection between ideology and media form, arguing that "Taboo News" about Sweden is emerging as a predictable commodity in the nascent political economy of radical right media. This media is structured by its surveillance of and antagonistic positioning in relation to the presumptive hegemony of the "mainstream", and thus continually validates itself as covering the news which will not be reported, or which is being actively suppressed, by "politically correct" public culture. The intensive circulation of "Sweden", therefore, cannot be understood in terms of representation solely, but must be comprehended structurally, in terms of the circuits of production that shape "Sweden" generically and commercially as the focus of news rendered true by its putative absence elsewhere in the news ecosystem.

The second section analyses these circuits by working backwards from Trump's pronouncement, following the cross-references and connections between actors and sites, and building up an inevitably partial but heuristic picture of the exchange value of "Taboo news". Methodologically, the data from far-right media material has been gathered by "snowballing" through this working backwards, following the links actors make between each other, and, from their output, sampling media texts which make titular reference to "Sweden" for the year before, and six months after, Trump's speech. The material analysed is all in English, and predominantly circulated within transatlantic networks, and to a limited extent within Swedish-based English language media. Given the porousness of transnational flows of information across borders, and the ease with which English language material circulates in Sweden, a study which could combine the material examined here with Swedish-language data would inevitably produce a different and richer discussion, and these linguistic parameters should be borne in mind as part of the interpretative framework.

\section{Sweden as digital palimpsest}

\section{Racialised spaces, anxious nations}

In the contemporary far-right imaginary, Sweden is presented as a "nightmare" of national dissolution, one being wrought in those multi-ethnic suburbs of Stockholm and Malmö that are the subjects of spectacular, mediatized racialization, depicted as ticking cultural time bombs that can be avoided elsewhere if only the right lessons are learnt, or imposed, in time. While the particular intensities of this image in an expansive supremacist-nationalist media scene is the focus here, it should be noted that these constructions are not confined to this milieu, or indeed to Sweden. In particular, the politics of immigration and integration in Europe during the last 30 years has involved significant political and mediated concentration on urban spaces that have come to represent, through the overlay of social problems and presumed identities, a putative "failure of multiculturalism" or immigration policy. 
The "problem area" within the nation-state conjures up a mesh of associations between racialized populations, spatial concentration and symbolic problematisation. The production of these spatial imaginaries can follow a spectacular logic, such as the "litany of myths" that, Finney and Simpson argue, clustered around the idea of "parallel societies" in northern England following riots in Bradford and Oldham in 2001, where "[...] segregation prevents integration, clashes with British culture, heightens tension and breeds violence" (2009, p. 162). In de Konig and Vollebergh's (2019) work on the racialization of areas of Amsterdam in Dutch public debate, the "iconization" of ethnically diverse neighbourhoods takes shape cumulatively, textured by irruptions of political narrative-making and "anxious public discourse" where "these sites provide a fertile setting for the staging of national dramas" and where residents must negotiate how "particular public discourses come to infuse and shape" their lives (p. 391). Similarly, while this paper cannot do justice to the significant sociology on urban, spatial segregation in Sweden in the English language literature, it requires emphasis that the far-right imaginaries under discussion are febrile intensifications of a historically pronounced, if thematically shifting focus on iconized neighbourhoods in Stockholm and Malmö as "problem zones", outside of the norms and respect for law and order held to prevail in Sweden as a whole (Pred, 2000; Schierup et al., 2014).

Sites that have been subject to spectacular events, or whose iconicity generates a certain degree of international attention, can come to play a relational role in the production of such imaginaries. Maria Stehle's work on Germany has compared how Der Spiegel reportage in the 1970s detected "Harlem symptoms" in the "emerging ghettos" of guest workers, a comparative focus replicated after the riots in Clichy-sous-Bois and wider Paris in 2005, where areas of Berlin become subject to speculation as to whether they were prone to similar forms of violence. The "ghetto space", Stehle (2006) argues, "[...] is both feared and needed: it shows both the importance and the impossibility of "integration"; it is the location of the threat to Europe and the space where the "other" needs to be restricted and violence needs to be contained" (p. 62).

The symbolic process that Stehle describes has evident mainstream political currency, as manifested in the concerted political focus on the Brussels suburb of Molenbeek - also referenced by Trump - as the "terrorist capital of Europe" in the aftermath of the November 2015 attacks in Paris (Cammaerts, 2015); or the presentation of the Danish "ghetto deal" law in 2018, which targets well-known urban areas with high proportions of "non-Western background" residents for interventions and where residents must, according to the Justice Minister Søren Pape Poulsen, "profess to the values required to have a good life in Denmark" (Ngo, 2018). With this wider generativity in mind, the focus of what follows hones in on the specific tropes and symbolic emphases which far-right assemblages prefer and circulate. What requires specific explanation is that while areas such as Molenbeek, Tower Hamlets in London, and various suburbs of Paris also feature prominently in this genre of "taboo news", the image of Sweden is tied to its "problem areas" far more intimately and insistently than that of Belgium, the UK or France to these equally sensationalised and stigmatized urban zones. It is this scalar intimacy which informs the first research question to be examined; why are dominant forms of racist projection particularly fixated on Sweden-as-nation in the current conjucture?

\section{Sweden as revenge fantasy}

Given the period under discussion, the prominence of Sweden in far-right media texts is in part a clear reaction to its vaunted role as the European country that accepted more refugees in 2015 than any other per capita in Europe, a fact subject to a volatile domestic discourse as to the proper relation between "solidarity and responsibility", and Sweden's image in the
Taboo news about Sweden 
IJSSP

$39,11 / 12$

1014

world (Krzyżanowski, 2018). However, sifting through the connotations actively attached to "Sweden" reveals a more enduring preoccupation with the country, and as a common orientation shared by divergent far-right tendencies. In the far-right imaginary, the "problem area" becomes a "no-go zone", that is, it is not only a racialised space that is made to symbolise national problems, it is a territory fully lost to the nation, conquered from without but also, crucially, surrendered from within. This double movement explains why the "no-go" zone is evidence of the betrayal of a particularly mythic white, European nation, and thus constructed as site of overlapping racial, sexualised and civilizational "revenge fantasies". However, the relational logic of these fantasies also requires explanation.

Writing in 2002 on the significant rise in white supremacist and far-right web pages and internet-facilitated networking, Les Back (2002) departed from the pronounced emphasis on functionalist assessments of the organisational uses of the internet to examine the forms of globalised imagination facilitated by an expansive far-right "cyber culture". For movements and activists based in different national contexts, "the rhetoric of whiteness becomes the means to combine profoundly local grammars of racial exclusion within a trans-local and international reach that is made viable through digital technology" (p. 633). A shared structure of feeling vested in "whiteness under threat" allowed for activists to represent local circumstances in terms that can be translated between contexts. Therefore, through shared "processes of substitution", representations of different racialized minorities "are commensurable with each other, in that, depending on circumstances, they can be substituted without changing the wider structure of this trans-local racist culture" (Back, 2002, p. 639). The argument I wish to propose here is that Sweden is rendered intelligible through comparable if more expansive logics of substitution, and it is this substitutional logic that allows Sweden to be mobilised in racist narratives of loss that are otherwise marked by important differences in emphasis. This mediatised fixation is best read through three related motifs that the idea of Sweden is made to provide - the betrayal of whiteness, the multicultural surrender to "Islamic takeover", and the feminised and feminist nature of hegemonic political culture.

The mythic image of Swedes as "the whitest of the whites" is a "[...] construction of Swedishness in relation to whiteness (that) can be traced back to the privileged position of Swedes in relation to the historical construction of the white race itself, a scientific discourse that was hegemonic for almost two hundred years" (Hübinette and Lundström, 2011). While that hegemony clearly no longer holds in these terms, the association between northern Europe and whiteness remains pronounced. In his study of "Nordic noir", for example, Ben Pitcher argues that the contemporary cultural currency of mediated Scandinavian-ness cannot be understood without understanding how Sweden seems to offer a compensatory modality of whiteness:

Bolstered by a longstanding association between whiteness and the north, Nordic culture stands as a symbolic point of origin, giving white people a set of coordinates to define who they are and what's important to them. It provides a fantasy of whiteness that is simultaneously distinctive and progressive. It provides a repertoire of moral orientations and stylistic positions that, in a variety of different contexts, delineate some aspirational ways of living, thinking, and being (2014).

This mode of progressive Whiteness is inseparable from this image of Sweden as a "good society" betraying itself; as David Crouch (2018) argued, the "Alt Right" storm of fake news about Sweden and refugees leveraged an Anglophone romanticisation not only of - a partially dismantled - Scandinavian social democracy, but also of the putative organicity of Nordic social life. "Non-European" migration to Sweden, and the spatial concentration of non-white bodies in "ethnic enclaves", symbolises the acuity of white loss. Sweden is at once a specific reference point and a generic coordinate in a mediated, affective white supremacist 
mapping of distributed racial pollution. Red Ice Radio, for example, which simulcasts from its website and YouTube, is a fixture in Sweden's historically highly developed, professionalised and differentiated far-right media scene (Ekman, 2014, 2018). Broadcasting in English, it also situates itself as a dissident voice seeking transnational solidarity. Its June 262017 edition, "Nordic News: the genocide of the Swedes" salutes its audience from "Sweden, the canary in the multicultural coalmine". The failed experiment of "importing a low IQ third world population" is a "globalist" (UN/American/Jewish/Soros) plot: an advanced instance of the resurgent idea of "white genocide".

A comparable rationale of orchestrated betrayal suffuses the media sites of the "counter-jihadist online network", the "large number of websites, blogs and communities (that) form a network that disseminates theories of an ongoing Islamic colonization of the West" (Ekman, 2014, p. 1987). Within this network, the second key dimension is prominent; the contention that demographic change is sliding into cultural-political threat. The elaboration of "Eurabia", or an "Islamification" of the "West" is fixated on "no-go zones" as incontrovertible evidence of this decline (Ekman, 2014; Lee, 2015). As Liz Fekete (2012) has argued, the field of anti-Muslim actors can be differentiated along a spectrum from those who regard "Islamic takeover" in conspiratorial terms - orchestrated, like white genocide, by "multicultural elites" - and those who regard it, relatively more benignly, as an inevitable consequence of liberal/multicultural naivety. In the transnational purview of the "counter-jihad", "Muslims" are also a substitutional population, in that "their" mere presence is sufficient to project comparable processes of dissolution everywhere. It is worth noting here that while the exemplary focus on Sweden was amplified by the 2015 border crisis, it substantively precedes it, and significant work was done by Nordic counter-jihadists, in English, to circulate this image. Two of Anders Breivik's most important citations in his "manifesto", 2083: A European Declaration of Independence, for example, focussed relentlessly on the dystopia-next-door as Norway's endarkened future. The blogger "Fjordman" (real name Peder Jensen) consistently returned to Sweden as the stark evidence of the inevitable costs of "Muslim immigration", particularly to a welfare state in denial as to the cultural basis of its sustainability (Jackson, 2013). Bruce Bawer (2011), author of The New Quislings: How the International Left Used the Oslo Massacre to Silence Debate About Islam, wrote in a similar vein for Frontpage Magazine in Bawer (2013) as to "Sweden's March into Oblivion: The Fruits of Denial": "Sweden is self-destructing, and more and more people are writing about it - but with very few exceptions, still not in the mainstream Swedish media, where denial continues to reign supreme".

The third dimension is closely imbricated to Islamophobic narratives of the cost of Muslim take-over. It is an explicitly gendered narrative indicated by the frequent instrumentalization and objectification of rape and sexual assault, and the vengeful register of "denial" is brought sharply into focus through this preoccupation. In a study of the remediation and circulation of an image of a Swedish woman taken after she has suffered a violent attack, Karina Horsti demonstrates how the image was shared and reproduced through Nordic far-right and counter-jihad blog networks within an "Islamophobic rape frame", and despite the wishes of the woman in the photo. Her analysis emphases the importance of visuality to its circulation, as the photograph circulated first as "evidence" and then as a meme template that allowed different narrative additions, such as "[...] "Muslim Rape, Feminist Silence" with the sub-text "Victim of Muslim gang rape in Sweden" (Horsti, 2016, p. 10). That "Sweden" has stuck to the decontextualised image as it circulates, Horsti (2016) argues, is significant, as it opens out a critical valence of the fantasy projection - Sweden is imagined as "feminist and white" (p. 10).

That is, it is not just that Sweden is constructed as a gendered racial imaginary, where the nation, like the female body, is vulnerable to violation and in need of the protection of "white border guard masculinities" (Keskinen, 2017). This rhetoric is assuredly mobilised, 
IJSSP

$39,11 / 12$

1016

and, as Sara Farris describes in wider European perspective, the political articulation of "femonationalism" involves convergence and affinities between the (far) right and some formations of liberal feminism that invoke the threat to national values posed by the uniquely patriarchal relations of Muslim culture, and facilitated by inadequate immigration and integration policies (Farris, 2017). Rather, "Sweden" is not just feminised, but feminist. That is, it has "engineered" a feminist culture which is sexually liberated, insufficiently dependent on white masculinity, in thrall to multiculturalism and the exotic other, and thus complicit in its own violation. "Sweden", therefore, is an ambivalent imaginary in the gendered politics of white nationalism and Islamophobia, as the defence of /lament for advanced cultures of equality is suffused with an antagonism towards feminism, blamed as a prime driver of social re-engineering, and thus generative of a disturbing co-dependency between protectionist and punitive desires.

To sum up these key dimensions of representation, it is evident that Swedish "problem areas" signify within a wider, politically distributed symbolic economy whereby spatialised concentrations of bodies and identities racialised as "non-western" - and particularly "Muslim" - come to stand in for anxieties over social cohesion and cultural belonging in the nation-state. This anxiety is frequently narrated in terms of histories of generosity and excess, histories that have produced the visible evidence of multicultural failure and immigration mismanagement (Lentin and Titley, 2011). Far-right modes of representation integrate both of these tendencies, while intensifying them through a mythology of betrayal and thus inevitable revenge. In particular, the convergence on feminism as indicative of both a wider political reputation for liberalism and social democratic equality, and the deliberate emasculation of the nation through "non-western" immigration is important to understanding, in the next section, the prevalence of sexual violence in news coverage. Similarly, the insistence on denial which underpins conspiratorial thought is increasingly elevated into a structuring condition of "taboo news".

\section{Taboo news: Sweden as commodity in the "altered media ecology"}

Taboo news and the productivity of denial

Shortly after Trump's comments at the Florida rally, Yochai Benkler et al. (2017) published the results of a study of $1.25 \mathrm{~m}$ news stories posted online between 1 April 2015 and the Presidential Election of 8 November 2016. Joining a burgeoning field of studies of "trolling" "fake news" and "political polarization" in the far-right milieu (for an overview see Tucker et al., 2018) the study provides a map of a "distinct and insulated media system" that is nevertheless integrated to and acts upon the wider media field in a number of specific ways. Their analysis of Facebook and Twitter news-sharing patterns positioned Breitbart News as the central node of a right-wing "knowledge community", that is, a mesh of relatively new media titles and platforms integrated through hyperlinks and sharing protocols and practice to larger and more established channels such as Fox News. This "altered media ecology" is characterised not by the somewhat techno-determinist notion of "filter bubbles", but rather by patterns of "asymmetric attention". That is, while "progressive" new outlets were not linked or circulated in the hyper-partisan media sphere, Breitbart and related outlets were widely discussed, linked to and responded to in liberal media discourse and journalism. While coverage was predominantly critical in tone, they argue, it granted significant agenda-setting power as "[...] it nonetheless revolved around the agenda that the right-wing media sphere set: immigration [...] just as Trump made this a focal point for his campaign, Breitbart devoted disproportionate attention to the topic" (Benkler et al., 2017).

It was these synergies, they note, that "[...] has created an environment in which the President can tell supporters about events in Sweden that never happened" (Benkler et al., 2017). Studies of far-right media production and communicative action have proliferated over the last few years, focussing on the impact of networked dynamics and affordances on 
movement coordination, mobilisation and communication (Ekman, 2018); the use of social media to intervene in news cycles and leverage publicity within established media routines (Froio and Ganesh, 2018); the opportunities provided by the informational architecture of the internet and connective media for disinformation, "astroturfing" and "meta-political" initiatives (Klein, 2012). In this section the analysis focusses on a very recent and thus little-researched phenomena; the emergence of a professional scaffolding of far-right media that intersects with and amplifies a variety of movements, but that also transcends them, and incorporates nascent forms of punditry, political celebrity, and entrepreneurial media ventures and collaborations. It is the growth of this terrain, in parallel to the intensified border crisis, that positioned "Sweden" as a key commodity in the "taboo news" economy. Given that, as Tucker et al. (2018) argue, studies of this "complex media ecosystem" must attempt to capture interactivity rather than rely on the analysis of discrete actors (pp. 28-29), this study takes Trump's original point of reference as a starting point, and traces and analyses communicative relations back from that point of "mainstream" irruption.

The day after his speech, Trump tweeted to clarify that he had been referring to a Fox News programme "concerning immigrants and Sweden" that had aired the night before his speech. This was a reference to an interview, on Fox's Tucker Carlson Tonight, with Ami Horowitz, introduced as a "documentary film-maker" who had been investigating "how Sweden became the rape capital of Europe". Fox's Tucker Carlson Tonight programme is one of the most popular programmes on Fox News, the most-watched cable news channel in the USA. Though the show ran into trouble in late 2018 - losing sponsors and advertisers following a monologue by Carlson where he suggested that "immigrants" make the USA "dirtier" (Lopez and Coaston, 2018) - in the period since the beginning of the Trump presidency it had attracted critical journalistic comment in the USA for the skill with which it "mainstreamed" white nationalist "talking points".

The investigative site Truthdig, for example, noted how Carlson departed from coded discussions of "illegal immigration" and its putative links to crime and other social costs, to criticising immigration and "cultural diversity" in the "ethnopluralist" terms associated, in the USA, with the then-nascent "Alt-Right" (Hawley, 2017, pp. 11-16). The narrative of an unfolding crisis in Sweden plots out the ethnopluralist insistence on the inevitability of conflict between incompatible cultures (Copsey, 2013). Thus Horowitz, the director of the predictably titled "Stockholm Syndrome" documentary, recounted how Sweden, which clings to a collective self-image as a "humanitarian super-power", found that its "open door" policy in 2015 led to an "absolute surge in gun violence and rape in Sweden". This reality, a reality under official denial, prompted him to make his documentary. The conceit of denial, as a recurring feature of the Sweden story, is subject to multiple variations. In the "Alt-Right" taxonomy, it stands in for "ethnomasochism", that is, cultivating or ignoring the racialised threat which will destroy your cultural identity and interests (Hawley, 2017).

Consequently, any criticism of taboo news from Swedish sources is easily parlayed into further evidence of studied myopia. A fact-check on Horowitz's documentary by the news site TheLocal.se revealed unfounded and erroneous claims in the documentary, and two police officers interviewed in the documentary told the daily newspaper Dagens Nyheter that their answers, which seemed to suggest a link between an increase in crime and refugee numbers, had been, like the BBC's narrative experiment, edited unscrupulously (Oltermann and Helmore, 2017). This pushback served to increase Horowitz's appearances in related news outlets to refute the criticisms, a dynamic which illustrates the generic aspect of taboo news - any criticism from the mainstream increases the "truth value" of the story under official denial. Some of these appearances were on the "central node" of Benckler's "altered media ecology", Breitbart. A special report on Breitbart by the monitoring organisation Hope Not Hate stated that "[...] Breitbart is not a news website or a media outlet in any ordinary sense and its staff are not mainstream journalists. Breitbart is a political project, with a specific
Taboo news about Sweden

1017 
IJSSP

$39,11 / 12$

1018

political agenda, staffed by willing propagandists" (Knowles, 2017, p. 3). Founded in 2007 by Andrew Breitbart, Breitbart News Network began as a "pro-freedom and pro-Israel" news site. According to David Niewert in his recent book Alt-America: The Rise of the Radical Right in the Age of Trump, after the appointment of Steve Bannon as Executive Chairman, "[...] Breitbart began specializing in coverage that supported white-nationalist narratives about black criminality and the supposed "threat" of immigration" (Neiwert, 2019: loc 3850-3870).

The currency of Sweden in elaborating this threat can be traced exactly to the establishment of Breitbart London in 2014. Horowitz was interviewed in December 2016 on Breitbart News Daily by Raheem Kassam, then senior advisor to Nigel Farage of UKIP, before becoming editor of Breitbart UK. In the Breitbart Daily News podcast of 19 January 2018, Kassam underlined how a focus on Sweden was important to the site's European strategy, as "[...] we have a bureau of a half a dozen people over in the United Kingdom and 16 of our biggest stories this year have been about Sweden". In fact, in 2017, the year of Trump's speech, a search using Breitbart's site search engine found 34 stories with headlines about the problem of immigrants in Sweden (the amount of articles mentioning Sweden and immigration is higher). As striking as this density of stories is the scale of Malmö's appearance in news headlines, without locative mention of Sweden. The stand-alone recognition of Malmö in an Anglo-American news site indicates the frequency with which the city is featured as the primary laboratory in Sweden's putatively "failed experiment" with migration and multiculturalism. In the stories published during this year, Malmö is consistently framed in the headline or article lede by a revolving series of tropes; "heavily-migrant populated Malmö", "multicultural Malmö", "the migrant stronghold of Malmö".

In the same year, Kassam published a book No Go Zones: How Sharia Law is Coming to a Neighbourhood Near You (2017), prefaced by his mentor Nigel Farage, in which Farage predicts that Kassam's "comprehensive documentation" could provide a good starting point for "debates on integration, assimilation, and the scale and speed of migration into the West" if only the truth about such areas was not assiduously avoided by "much of the establishment media that spends its time in denial". As Farage makes clear, what is at stake is "the West", and Kassam's analysis rapidly telescopes in to those sites that corrode the West "from within". Chapter 4 is entitled "From Sweden, with rape", and, in a version of the BBC's stylised set-up, moves briskly in two paragraphs from mandatory wonder at the modernity of the Öresund bridge to approval at Malmö's cleanliness - "there's no way this place has No Go Zones, I thought to myself" - to first contact with Rosengård, "Malmö's primary No Go Zone". The centrality of Sweden to Breitbart's coverage of a European "migration crisis", therefore, would appear to have had a clear commercial calculus, and also an audience rationale - presuming that the idea of Sweden in crisis was familiar enough to an Anglo-American readership to anchor the focus, but also distant enough to secure the space required by the generic taboo reflex. Every other news site is in denial, except us.

\section{Sweden as sociological alibi in the far-right ecosystem}

In fact, the critical publicity generated by Trump's comments precipitated wider responses in this media ecosystem, underlining the commodified value of "Sweden" in circulation. Within this exchange value there are variations in use value, and one of the most prevalent is the status of news about Sweden as a sociological alibi for far-right networking. That is, Sweden as a news topic is regularly used to structure contact and dialogue between the self-styled "independent journalists" of the far-right milieu, and more radical and overtly racist figures. According to Jared Holt, a researcher with the monitoring group Right Wing Watch, this careful cultivation of affinity and distance between notionally independent journalists and movement figures or ideologues is a structuring feature of the media system:

The punditry faction of YouTube, much like cable news, thrives on collaboration and guest appearances on other pundits' channels. These right-wing YouTube commentators believe that by 
bolstering one another they can break through "fake news" mainstream media narratives and spread their own flavour of political analysis. The most extreme of these commentators will identify YouTube pundits slightly closer to the center-Right than them, and appear on their programs to share their viewpoints. They then use this access to a larger platform to recruit more people to their own pages, where they espouse extremist views with even less restraint (Holt, 2018).

A figure such as Lauren Southern, who left the Canadian alt-right news site Rebel Media in 2017 for her own YouTube channel of 519,000 subscribers, is a useful example of this process. She is not openly aligned with any one group, but through the "let's just ask the question" format of her discussion show creates social media space for, and in turn gains audiences from, wider movements and ideological milieu. Her Rebel Media show "Stand Off" on 24 June 2016, for example, used as a studio backdrop a screen grab from the "fake news" aggregation site Speisa to circulate the story "Sweden to become a Third World Country by 2030, according to the UN". This plausible future scenario, she argued, requires understanding that "Immigrants to Europe differ from native Europeans in ways that are much more significant than just skin colour. And no matter how much the left deny it, this change is creating deep issues for European culture". Her discussion guest was Martin Sellner, spokesperson for Generation Identity, the attempted pan-European movement based on Génération Identitaire (the youth wing of the French extreme right group Bloc Identitaire). For Southern, "new" Identitarian movements have "emerged with the aim of reinvigorating European culture", but also as a form of nationalism that can avoid "succumbing to the racism and fascism of past European nationalist groups". In this conversation, overtly distanced from "the racism of the past", Sweden is seamlessly inserted into a rendition of the "great replacement" of indigenous European populations conspiracy theory most recently codified in Camus's (2011) Le Grand Remplacement, and widely circulated from the extraordinarily productive French online fachosphère through the identitarian networks that expanded during the borders crisis (see Nilsson, 2018; Gimenez and Voirol, 2017).

In these examples, taboo news about Sweden is oriented towards niche audience-building, primarily through channel building on YouTube. And, much as mainstream current affairs programming is routinely structured by narrative convention, what is clear from this data is that the structuring conceit of telling the untellable truth also produces formulaic, repeated story forms. The generic development of taboo news is particularly suited to the formats and modes of interaction of YouTube, where, as Rebecca Lewis (2018) has recently demonstrated, a critical mass of far-right "political influencers" is succeeding in building a "dense system" of cross-referentiality and channel/brand boosting, particularly by attempting to establish an "alternative sense of credibility based on relatability, authenticity and accountability" (p. 1). However, casting a wider net in the social media-enabled ecology indicates how taboo news does not simply thrive through circuits of confirmation, but also comes to circulate and blend into informational flows across platforms in what Andrew Chadwick has usefully termed the "hybrid media system" (Chadwick, 2013).

Quite clearly, "taboo news" benefits from the forms of circulation and re-mediation associated with "fake news", or what Adam Klein, with more precision, terms "information laundering"; using professional design standards, astro-turfed research entities and the search architecture of Google to legitimise disinformation through circulation, repetition and visibility. For example, on 7 January 2016 the London based newspaper The Independent published a story "Sweden and Denmark have highest rates of sexual harassment in Europe" (Matharu, 2016), about a European Agency for Fundamental Rights report on the prevalence of sexual assault in EU countries. The article mentions the variations in legal definitions of sexual assault across jurisdictions, and the significant differences in social and institutional support for women to report their experiences, before turning primarily to a claim by the Gatestone Institute that "Sweden is the rape capital of the West". As the article 
IJSSP

$39,11 / 12$

1020

summarises, 'According to the Institute, the fact that "in 1975 the Swedish parliament unanimously decided to change the former homogenous Sweden into a multicultural country" was of relevance when discussing why the number of rapes had increased.

Arguably, the image of a "homogeneity" betrayed by concerted political action should have raised suspicion, however the article depends entirely on the Gatestone link for its analysis. The Gatestone Institute, according to a Hope Not Hate report on the transnational "Counter Jihad movement", is a "New York City-based think tank (that) publishes and promotes anti-Islam material" (Lowles et al., 2017, p. 138). The Independent story links to a report on its website written by Ingrid Carlqvist and Lars Hedegaard, co-editors of Dispatch International, a paper launched in 2012 at a major European "counter-jihad" conference and whose inaugural front page story reported how the "Muslim population in Sweden and Denmark doubled in 14 years". The report does not provide data on the ethnic background of sexual offenders, but weaves a pseudo-correlation between immigration data, a timeline of "multicultural legislation" and numerically increased reporting of sexual assaults over time to reach the "rape capital of the West" conclusion. This sourcing by The Independent demonstrates how the kind of self-confirming activist talking points given generic shape and coherence by taboo news formats also easily leak and bleed into mainstream circulation, that is, into the very antagonists that provide "taboo news" with its definitional other.

\section{Conclusion}

Taking President Donald Trump's reference as an orientation point, this article has aimed to examine the fantastical construction of Sweden as a racialised space and cautionary tale in the transnational, multi-scale field of far-right digital media. In keeping with the thematic focus in this special issue on raced spaces, the argument first underlined the generativity of Sweden as a digital palimpsest, anchored in the comparatively unique ways in which Sweden the - overly liberal, multiculturalist, feminist - nation is deterministically associated with its indicative "no-go zones". It contends that while these processes of symbolic racialization are familiar, the particular intensity of the focus on Sweden depends on the emerging political economy of "taboo news". Taboo news, generically, requires the certainty of its own denial; a fundamental condition for this construction of Sweden is that the audience is being given access to a truth which is confirmed by its absence from other sources. "Sweden" thus takes shape as a particular repository of myths, fantasies and projections, but also as a generic device, a dystopic future which positions its transnational audience not just spatially, watching a catastrophe somewhere else, but also temporally, as possessed of knowledge as to a possible future here, unless some form of action is taken.

In bookending the specific exploration of the far-right media environment with evidence of how this imaginary circulates in the mainstream, the article draws attention to how images of racialised urban spaces in the troubled nation have a political and affective valence beyond the media ecosystem in which they are gestated. That this rhetoric of a future-to-be-averted can be mobilised by figures such as Trump or Farage indicates how the iconic space, "lost to the nation", can be integrated to a familiar rationale in the politicisation of migration, pointing to catastrophes unfolding elsewhere as the factual, pragmatic justification for border violence. Thus, this specific invocation of Sweden also involves a generic demand to look elsewhere, to that racialised space conjured as empirical proof of the problem of immigration and multiculture, and which consequently functions as an urgent confirmation of the need to enact a politics that averts their present becoming our future. This gesture is politically pronounced beyond the exaggerated spectacles of far-right projection and "populist" invention, and while the question cannot be treated here with the depth it requires, it is nevertheless important to examine further why racialised spatial imaginaries consistently accrue such symbolic traction and affective investment. 


\section{References}

Back, L. (2002), “Aryans reading Adorno: cyber-culture and twenty-first-century racism”, Ethnic and Racial Studies, Vol. 25 No. 4, pp. 628-651.

Batchelor, T. (2017), "Nigel Farage investigated by Ofcom for saying 'Sweden is rape capital of Europe'”, The Independent, 20 March, available at: www.independent.co.uk/news/uk/politics/ nigel-farage-ofcom-investigation-sweden-rape-capital-europe-a7639401.html

Bawer, B. (2011), The New Quislings: How the International Left Used the Oslo Massacre to Silence Debate About Islam, Broadside, New York, NY.

Bawer, B. (2013), "Sweden's march into oblivion: the fruits of Denial”, Frontpage Magazine, 19 December, available at: www.frontpagemag.com/fpm/213603/swedens-march-oblivion-brucebawer (accessed 25 November 2018).

Benkler, Y., Faris, R., Roberts, H. and Zuckerman, E. (2017), "Study: Breitbart-led right-wing media ecosystem Altered Broader Media agenda", Columbia Journalism Review, 3 March, available at: www.cjr.org/analysis/breitbart-media-trump-harvard-study.php (accessed 25 November 2018).

Cammaerts, B. (2015), "There is no Belgian problem with radical Islam - only a European one”, Europp LSE blog, 18 November, available at: https://blogs.lse.ac.uk/europpblog/2015/11/18/there-is-nobelgian-problem-with-radical-islam-only-a-european-one/

Camus, R. (2011), Le Grand Remplacement (introduction au remplacisme globale), David Reinharc, Paris.

Copsey, N. (2013), "Fascism...but with an open mind: reflections on the contemporary far-right in western Europe", Fascism; Journal of Comparative Fascist Studies, Vol. 2 No. 2, pp. 1-17.

Chadwick, A. (2013), The Hybrid Media System: Politics and Power, OUP, Oxford.

Crouch, D. (2018), "From Fika to fake news: what's left of the Swedish Model", Nordicom Information, Vol. 40 No. 2, pp. 29-33.

De Konig, A. and Vollebergh, A. (2019), "Ordinary icons: public discourses and everyday lives in an anxious Europe”, American Anthropologist, Vol. 121 No. 2, pp. 390-402.

Ekman, M. (2014), "The dark side of online activism: Swedish right-wing extremist video activism on YouTube”, MedieKultur, Vol. 56, pp. 79-99.

Ekman, M. (2018), "Anti-refugee mobilization in social media: the case of soldiers of Odin", Social Media + Society, Vol. 4 No. 1, pp. 1-11.

Farris, S. (2017), In the Name of Women's Rights: The Rise of Femonationalism, Duke University Press, Durham, NC.

Fekete, L. (2016), "Flying the Nativist Flag", Open Democracy, 10 June, available at: www.opendemocracy. net/uk/austerity-media/liz-fekete/flying-nativist-flag (accessed 25 November 2018).

Fekete, L. (2012), "The Muslim conspiracy theory and the Oslo massacre", Race \& Class, Vol. 53 No. 30, pp. 30-47.

Froio, C. and Ganesh, B. (2018), "The transnationalisation of far right discourse on Twitter", European Societies, Vol. 21 No. 4, pp. 513-539, available at: www.tandfonline.com/doi/full/10.1080/ 14616696.2018.1494295 (accessed 5 January 2019).

Gimenez, E. and Voirol, O. (2017), “Les agitateurs de la toile: L'internet des droits extrêmes”, Réseaux, Vol. 2 Nos 202-203, pp. 9-37.

Hawley, G. (2017), Making Sense of the Alt-Right, Columbia University Press, New York, NY.

Holt, J. (2018), "White Supremacy figured out how to become YouTube famous", Right Wing Watch, available at: www.rightwingwatch.org/report/white-supremacy-figured-out-how-to-becomeyoutube-famous/ (accessed 5 January 2019).

Horsti, K. (2016), "Digital Islamophobia: the Swedish woman as a figure of pure and dangerous whiteness", New Media \& Society, Vol. 19 No. 9, pp. 1440-1457.

Hübinette, T. and Lundström, C. (2011), "The double-binding power of Swedish Whiteness through the mourning of the loss of 'Old Sweden' and the passing of 'Good Sweden', Nordic Journal of Feminist and Gender Research, Vol. 19 No. 1, pp. 42-52.

Taboo news about Sweden 
IJSSP

$39,11 / 12$

1022

Jackson, P. (2013), “The license to hate: Peder Jensen's Fascist Rhetoric in Anders Breivik's Manifesto 2083: a European Declaration of Independence”, Democracy and Security, Vol. 9 No. 3, pp. 247-269.

Keskinen, S. (2017), "The 'crisis' of white hegemony, neonationalist feminities and antiracist feminism", Women's Studies International Forum, No. 68, pp. 157-163.

Klein, A. (2012), "Slipping racism into the mainstream: a theory of information laundering", Communication Theory, Vol. 22, pp. 427-448.

Kyriakides, C. (2017), “Words don't come easy: Al Jazeera's migrant-refugee distinction and the European culture of (mis)-trust”, Current Sociology, Vol. 65 No. 7, pp. 933-952.

Krzyżanowski, M. (2018), “'We are a small country that has done enormously lot: the 'refugee crisis' and the hybrid discourse of politicizing immigration in Sweden", Journal of Immigrant \& Refugee Studies, Vol. 16 Nos 1-2, pp. 97-117.

Lee, B. (2015), "A day in the 'Swamp': understanding discourse in the online Counter-Jihad Nebula", Democracy and Security, Vol. 11, pp. 248-274.

Lentin, A. and Titley, G. (2011), The Crises of Multiculturalism: Racism in a Neoliberal Age, Zed Books, London.

Lewis, R. (2018), "Alternative influence: broadcasting the reactionary right on YouTube", Data \& Society, Media Manipulation Research Initiative, pp. 1-58.

Lopez, G and Coaston, J. (2018), "Tucker Carlson suggested immigration makes America 'dirtier'. It's costing him", Vox, 18 December, available at: www.vox.com/policy-and-politics/ 2018/12/17/18144620/tucker-carlson-immigration-dirtier-advertiser-pacific-life (accessed 20 September 2019).

Lowles, N., Mulhall, J., Lawrence, D. and Murdoch, S. (2017), Breitbart: A Right-Wing Plot to Shape Europe's Future, Hope Not Hate, London.

Matharu, H. (2016), "Sweden and Denmark have highest rates of sexual harassment in Europe", The Independent, 7 January, available at: www.independent.co.uk/news/world/europe/swedenand-denmark-have-highest-number-of-sexual-assaults-in-europe-a6800901.html

Mihelj, S., Bajt, V. and Pankov, M. (2009), "Television news, narrative conventions and national imagination”, Discourse \& Communication, Vol. 3 No. 1, pp. 57-58.

Ngo, M. (2018), “No ghettos in 2030': Denmark's controversial plan to get rid of immigrant neighbourhoods", Vox, 3 July, available at: www.vox.com/world/2018/7/3/17525960/denmarkchildren-immigrant-muslim-danish-ghetto (accessed 7 January 2019).

Neiwert, D. (2019), Alt-America: The Rise of the Radical Right in the Age of Trump, Verso, London.

Nilsson, P.-E. (2018), French Populism and Discourses on Secularism, Bloomsbury, London.

Ojala, M. and Pöyhtäri, R. (2018), "Watchdogs, advocates and adversaries: journalists' relational role conceptions in asylum reporting", Media and Communication, Vol. 6 No. 2, pp. 168-178.

Oltermann, P. and Helmore, E. (2017), "Swedish police comments 'taken out of context' in film cited by Trump", The Guardian, 20 February, available at: www.theguardian.com/world/2017/ feb/20/swedish-police-comments-taken-out-of-context-in-film-cited-by-trump (last accessed September 22 2019).

Pred, A. (2000), Even in Sweden: Racisms, Racialized Space, and the Popular Geographical Imagination, University of California Press, Oakland, CA.

Schierup, C.-U., Ålund, A. and Kings, L. (2014), "Reading the Stockholm riots - a moment for social justice?”, Race \& Class, Vol. 55 No. 3, pp. 1-21.

Stehle, M. (2006), "Narrating the ghetto, narrating Europe: from Berlin, Kreuzberg to the Banlieues of Paris", Westminster Papers in Communication and Culture, Vol. 3 No. 3, pp. 48-70.

Trilling, D. (2018), Lights in the Distance, Pan Macmillan, London. 
Tucker, J.A., Guess, A., Barberá, P., Vaccari, C., Siegel, A., Sanovich, S., Stukal, D. and Nyhan, B. (2018), Social Media, Political Polarization and Political Disinformation: A Review of the Scientific Literature, William + Flora Hewlett Foundation.

Winter, A. (2017), “Charlottesville, far-right rallies, racism and relating to power", Open Democracy, 17 August, available at: www.opendemocracy.net/aaron-winter/charlottesville-far-right-ralliesracism-and-relating-to-power (accessed 25 November 2018).

\section{Further reading}

Abdel-Fadil, M. (2016), “The 'Rape Game': framing the Cologne and Stockholm events”, Religion Going Public 7 March, available at: http://religiongoingpublic.com/archive/2016/the-rape-gameframing-the-cologne-and-stockholm-events (accessed 24 November 2018).

Berinsky, A.J. (2017), "Rumors and health care reform: experiments in political misinformation", British Journal of Political Science, Vol. 47 No. 2, pp. 241-262.

Ling, J. (2017), "Follow the money", Vice News, 22 August, available at: https://news.vice.com/en_ca/ article/wjz73q/inside-rebel-medias-big-money-anti-islam-crusade (accessed 5 January 2018).

Ong, J.C. and Cabañes, J.V.A. (2018), “Architects of networked disinformation: behind the scenes of troll accounts and fake news production in the Philippines", The Newton Tech4Development Network/British Council.

Papacharissi, Z. (2014), Affective Publics: Sentiment, Technology, and Politics, Oxford University Press, Oxford.

Pitcher, B. (2014), Consuming Race, Routledge, London.

\section{Corresponding author}

Gavan Titley can be contacted at: gavan.titley@mu.ie

For instructions on how to order reprints of this article, please visit our website: 